\title{
Completion Time Dynamics For Master's And Doctoral Studies At Makerere University
}

Robert Wamala, Makerere University, Uganda Joseph C. Oonyu, Makerere University, Uganda

\begin{abstract}
This paper examines the dynamics of completion time of master's studies and how such dynamics relate to those of doctoral studies at Makerere University, Uganda. The assessment is based on administrative data of 605 master's degree students at the University in the 2004 and 2005 enrollment cohorts. The total elapsed time from first enrollment to submission of final dissertation copy was adopted as a measure of completion time. A time-to-event approach in a Cox model was applied in the investigations. A median completion time of 3.8 years (range, 1.8-5.9) suggests a delayed completion of studies. The established associations, modeled by a range of candidate, candidature, and institutional variables including discipline area corroborate the results obtained by the analysis of doctoral completion time at the University. The findings suggest that master's completion dynamics mirror those of doctoral studies at the University.
\end{abstract}

Keywords: Completion Time Dynamics For Master's and Doctoral Students; Graduate Study Completion Time, Makerere University

\section{INTRODUCTION}

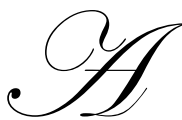

lthough persistence in graduate programs is widely regarded as an important topic in the literature of higher education, many such works focus on doctoral studies. An abundance of literature, dating back to the 1980s, addresses the completion, completion time, and non-completion of doctoral studies (e.g., Tinto, 1987, 1993; Sheridan \& Pyke, 1994; Wright \& Cochrane, 2000; Martin, MacLauchlan, \& Karmel, 2001; Bourke, Holbrook, \& Lovat, 2004, 2006; Grebennikov \& Shah, 2007; Wamala, Oonyu, \& Ocaya, 2011). In the literature, doctoral completion is associated with a number of interrelated factors comprising, but not limited to, the following: i) student characteristics such as age at commencement (Wamala et al., 2011; Wright \& Cochrane, 2000), gender (Wright \& Cochrane, 2000; Council of Graduate School, 2008; Siegel, 2005; Vladimir, 2010), full-time versus part-time study (Ismail \& Abiddin, 2009), and national citizenship (Wamala et al., 2011; Wright \& Cochrane, 2000); ii) institutional factors comprising discipline area (for example, Elgar, 2003; Wright \& Cochrane, 2000; Wamala et al., 2011; Bourke et al., 2004) and entry qualifications (e.g., Tinto, 1993); and iii) candidature characteristics such as financial assistance (e.g., Tinto, 1993; Charles, 2002), supervision (Chris, 2005), indirect help such as outside contacts (Hakserver \& Manisali, 2000), and the demands of outside employment (D'Adrea, 2002).

In light of the rich literature on doctoral studies, the role of persistence in master's programs has yet to be as thoroughly examined. Recent literature on master's programs is focused on completion statistics rather than on how these statistics relate to the aforementioned variables assessed for doctoral studies (Mugimu, Nakabugo, \& Katunguka, 2009; Wisdom, 2008, 2010; Ismail \& Abiddin, 2009; Sanders, Guwatudde, \& Alexander, 2008). Similar to the works examining doctoral studies, these studies report that the time required to complete a master's program has increased in "recent years." Wisdom's 2008 six-year completion estimate of $11 \%$ for students attending the member universities of the Partnership for Higher Education in Africa (PHEA) and Sanders et al.'s (2008) 17\% rate for students attending the Makerere University School of Public Health (MUSPH) do not show otherwise. While a 
delayed completion of master's studies at these institutions is observed, the dynamics of these completions remain unknown. The dilemma is whether there is need for independent comprehensive investigations of persistence in master's studies after the doctoral assessment has been performed. This study therefore seeks to examine whether the dynamics of completion time in doctoral studies could be adopted as a basis for explaining the situation in master's programs for a particular academic institution. Certainly, the variables and/or associations established in the investigations of doctoral completion time at the University (Wamala et al., 2011) provide a basis for pursuing such an explanation.

\section{DATA AND METHODS}

The investigations were based on administrative data of master's students at Makerere University in the 2004 and 2005 enrollment cohorts. A total of 605 records, comprising 457 enrollees who had completed their studies by the time of data collection and 148 enrollees in advanced stages of their dissertations (about to submit or already submitted reports for external review), were used in this study. Those in the advanced stages of their dissertations were considered censored and their enrollment time determined by the time of data compilation - November 2010. The total elapsed time from first enrollment to submission of final dissertation copy after a VIVA was adopted as a measure of completion time (Sheridan \& Pyke, 1994). In light of the right-skewed nature of graduate student's completion time reported in prior studies (for example, Wamala et al., 2011; Bourke et al., 2004), a time-to-event (survival) approach was applied in this work. The analysis was performed in three stages. First, a descriptive summary of the duration and probability of completion, which is the survival function, was presented following the Kaplan-Meier (1958) estimator. Second, differentials in survival across the potential variables (student characteristics, candidature characteristics, and institutional factors including discipline area) were investigated and associations were examined using the Log-Rank Chi-square test (Mantel, 1966; Peto, 1972). Third, the Cox proportional hazard regression, a semi-parametric model, was adopted to establish the collective net-impact of the variables (Cox, 1984). However, only variables with a probability value (p-value) of 0.25 or lower (obtained from the Log-Rank test) were considered for further investigation at the multivariate stage (Hosmer, Lemeshow, \& May, 2008).

\section{RESULTS OF THE STUDY}

The master's enrollees examined in this study perform full-time research and coursework at the University and are characterized as follows. Predominantly Ugandan by nationality (96.5\%), most enrollees are married (71.4\%) and male (62.3\%); the median age at the commencement of master's studies is 29 years (range, 20-53). Approximately four out of every nine students (44\%) were in the 2004 enrollment cohort. The vast majority (99.8\%) had Bachelor's Degree as their entry academic qualifications to master's studies.

\section{Completion Time of Master's Studies}

Because completion time does not span the entire real line $(0, \infty)$, the assumed normality of the variable is unreasonable. Thus, the variable was subjected to the Shapiro-Wilk test for non-normality (Shapiro \& Wilk, 1965). The test results (excluding censored observations) provide evidence for the existence of certain types of "nonnormality" in the data $(n=430 ; p<0.01)$; a similar test using the entire dataset does not suggest otherwise $(n=605$; $\mathrm{p}<0.01$ ). Similar to the doctoral assessment of studies at the University (Wamala et al., 2011), the normality assumption of the completion time in this study was not supported. Table 1 presents a descriptive summary of master's completion time, accounting for the censored observations. However, the summary excludes students registered for a Master's in Medicine $(\mathrm{n}=27)$ even though they had completed their studies by the time of data collection. These data are excluded because the stipulated completion time of this program is three years, whereas the other programs stipulate only two years (Makerere University, 2009). 
Table 1: Descriptive summary of Master's Completion Time

\begin{tabular}{ccccccc}
\hline $\mathbf{n}^{\mathbf{a}}$ & Min & Max & Median & Std. Error & \multicolumn{2}{c}{ 95\% CI [Median] } \\
\cline { 3 - 7 } & & & & Lower & Upper \\
\hline 430 & $21(1.8)$ & $71(5.9)$ & $47(3.8)$ & 0.09 & $44(3.7)$ & $48(4.0)$ \\
\hline
\end{tabular}

Note. Completion Time is expressed in months (years).

${ }^{\text {a}}$ Enrollment figure excludes students registered for Master's in Medicine.

According to results in Table 1, the median completion time of master's studies excluding the censored observations is 3.8 years (range, 1.8-5.9). Certainly, the figure is significantly higher than the stipulated two-year period, thus indicating delayed completion of master's studies at the University. However, the median completion time of students enrolled in the Master's in Medicine (3.1 years; range, 2.8-4.6) compares favorably with the stipulated three-year period.

\section{Rate of Completion of Master's Studies}

The rate of completion of the studies was evaluated using a Cox-PH regression; the Efron method of handling ties was also adopted. The variables that satisfied the inclusion criterion for consideration at the multivariate analysis comprised sex, nationality, employment status, prior research or teaching experience, broad field of study/discipline area, enrollment cohort, status of financial assistance, and availability of any other academic qualifications (Degree, Diploma, Certificate, etc.). Alternatively, the variables excluded from the multivariate assessment were marital status and age at commencement of master's studies; it is highly unlikely that these variables will contribute anything to the final model. Table 2 presents regressions estimates of the rate of completion of master's studies on the seven potential predictors.

Table 2: Rate of Completion of Master's Studies stratified by the Year of Enrollment

\begin{tabular}{|c|c|c|c|c|}
\hline Variables $^{\mathrm{a}}$ & Coef. & HR $(95 \% \text { CI })^{b}$ & Std. Err & p-value \\
\hline \multicolumn{5}{|c|}{ Research Experience } \\
\hline Experience Had & . & 1 & . & . \\
\hline None & -0.064 & $0.93(0.74-1.17)$ & 0.108 & 0.576 \\
\hline \multicolumn{5}{|c|}{ Employment Status } \\
\hline Employed & . & 1 & . & . \\
\hline Not-Employed & 0.274 & $1.31(0.93-1.85)$ & 0.232 & 0.121 \\
\hline \multicolumn{5}{|c|}{ Any other Qualification } \\
\hline Yes & . & 1 & & \\
\hline No & 0.080 & $1.08(0.87-1.38)$ & 0.119 & 0.468 \\
\hline \multicolumn{5}{|l|}{ Nationality } \\
\hline Ugandan & . & 1 & . & . \\
\hline Non-Ugandan & 0.587 & $1.80(1.06-3.04)$ & 0.480 & 0.028 \\
\hline \multicolumn{5}{|l|}{ Sex } \\
\hline Male & . & 1 & . & . \\
\hline Female & 0.005 & $1.00(0.82-1.23)$ & 0.104 & 0.955 \\
\hline \multicolumn{5}{|c|}{ Financial Assistance } \\
\hline No Assistance & . & 1 & . & . \\
\hline Assistance Held & 0.029 & $1.03(0.67-1.58)$ & 0.221 & 0.893 \\
\hline \multicolumn{5}{|l|}{ Discipline Area } \\
\hline Science & $\cdot$ & 1 & . & . \\
\hline Arts & -1.044 & $0.35(0.28-0.43)$ & 0.036 & 0.000 \\
\hline
\end{tabular}

Note. Likelihood Ratio Chi-square $(7)=114.5, \mathrm{p}<0.001, \mathrm{n}=561, \mathrm{AIC}=4178.4$

${ }^{a}$ Bold variable items represent reference categories adopted

${ }^{\mathrm{b}}$ Represents hazard ratio and their corresponding 95\% Confidence Interval 


\section{Regression Diagnostics}

The following three diagnostic tests were performed. First, the global and detailed proportionality tests of the hazards were satisfied $(\mathrm{p}>0.05)$. In doing so, the model was stratified by the year of commencement despite that this variable yielded a significant association with the rate of completion $(\mathrm{p}<0.05)$. Prior to the stratification, the year-of-commencement variable violated the proportionality assumption of the Cox model. The approach minimized the Akaike Information Criteria (AIC $=4178.4$ vs. 4766.5), thus implying a better overall fit (Akaike, 1974). Second, the specification errors of the link function in Table 3 show that the log hazard function was well specified, as predicted by the Hat-statistic (_hat: p < 0.05); the Hat-square statistic (_hatsq) shows that no additional variables were significant $(\mathrm{p}>0.05)$. Third, the predictive power of the model was evaluated using Harrell's C concordance statistics (Harell, Lee, \& Mark, 1982, 1996); concordance measures show that by using the predictors, the Cox model correctly identifies the order of completion times approximately $65 \%$ of the time (Harrell's $\mathrm{C}=0.647$, Somers' D = 0.2948).

Table 3: Specification Errors of Link Function

\begin{tabular}{llll}
\hline Log-Hazard Function $^{\text {a }}$ & Coef. & Std. Err & p-value \\
\hline _hat & 1.011 & 0.227 & 0.000 \\
hatsq & -0.057 & 0.252 & 0.821 \\
\hline
\end{tabular}

Note. Specification Errors of Cox model in Table 2

${ }^{a}$ Exponential form of the dependence of the hazard function on the predictors

\section{Summary of the Findings}

The results shown in Table 2 indicate that significant associations with the rate of completion were observed for the variables citizenship and discipline area $(\mathrm{p}<0.05)$. These results can be summarized as follows.

- $\quad$ Master's students in the Arts had a 65\% reduced rate of completion compared to those in the Sciences $($ Haz. Ratio $=0.35)$.

- International students (non-Ugandans) had a 1.8-fold increased rate of completing their masters studies compared to Ugandan students (Haz. Ratio $=1.80)$.

Conversely, non-significant associations with the rate of completion of master's studies at the University were observed for the variables age at commencement, gender, marital status, status of prior studies/qualifications, employment and financial assistance towards tuition, and research and/or living allowances $(\mathrm{p}>0.05)$. In other words, the completion time of master's studies at the University did not vary significantly by these variables.

Though no statistical inference can be made about the stratification variable (i.e. enrollment cohort status), the application of a stratified Cox model is an indication of a non constant hazard function across levels of this variable. In the bivariate assessment using to the Log-Rank test, timely completion was more likely among the 2004 master's enrollment cohort $(p<0.05)$. Thus, suggestions of enrollment cohort differentials in completion time of master's studies at the University are supported.

\section{DISCUSSION}

In this work, the completion time of master's studies was observed to be right skewed; thus, the normality assumption was violated. The results presented here contribute to the literature that has reported the skewed nature of the completion time of graduate studies (e.g., Bourke et al., 2004; Wamala et al., 2011). Therefore, these results support the aptness of implementing a time-to-event (survival) approach in a Cox-regression for modeling such data, as opposed to assuming the normality of graduate completion time in the application of an ordinary least squares (OLS) multiple linear regression. Certainly, the normality assumption could distort relationships and significance tests, resulting in questionable results and conclusions drawn from the data (Osborne \& Elaine, 2002). The median completion time of 3.8 years (95\% CI $3.7-4.1$ ) indicates a delayed completion of master's studies at the University. Although this value compares favorably with the four-year maximum permissible period of master's candidature described in the University Human Resource Manual (Makerere University, 2009, p. 53), the completion time is 
longer than the stipulated two-year period of master's training at the University. Similar findings were obtained in the investigation of doctoral studies at the University, where the estimated completion time of 5.0 years is longer than the stipulated three-year candidature period (Wamala et al., 2011). Together, both statistics (for both master's and doctoral studies) illustrate a delayed completion of studies at the University.

Following the Cox model in a range of candidate, candidature, and institutional variables including discipline area, several associations established in the 2011 study of doctoral completion time at the University were supported. Particularly, both studies reveal the timely completion of students in the Sciences, non-Ugandan students, and those students in earlier enrollment periods. In a related study of Makerere University that adopts the student perspective, Mugimu et al. (2009) observe the high enrollment of student in the Arts, which presents a heavy teaching, supervisory, and administrative workload. Furthermore, student isolation was more realized in the Arts; these aspects contribute to the delayed completion of students registered in graduate programs at the university. With regards to the enrollment cohorts of graduate studies at the University, both studies revealed a reduced rate of completion among enrollees registered in the "recent periods," an indication of an increase in the completion time of graduate studies of the University.

However, the rates of completion for both master's and doctoral students at the University was not significantly related to the variables gender, marital status, financial assistance (tuition, research and/or living allowance), work experience, prior performance (CGPA), and qualifications. Unlike studies that have indentified timely completers among the financially aided (e.g., Ismail \& Abiddin, 2009; Mugimu et al., 2009; Saint John, 2000; Tinto, 1993; Valentine, 1997), this work presents results for graduate students (both master's and doctoral) at the University that suggest otherwise. The findings suggest that these students benefit from extending their candidature beyond the stipulated periods. In a related study of non-completion of doctoral studies at the University, students with financial assistance were observed to stay beyond five years rather than withdraw (Wamala et al., 2011); it would be unsurprising if master's students at the University receiving financial assistance towards tuition, research, and/or living allowance are similar. In light of the fact that students with financial assistance are often selected because of their impressive grades, the hypothesis of timely completion of these students is not supported. The findings corroborate the recent 2011 investigations of doctoral studies at the University in which no significant association with the rate of completion was observed for the students who were financially assisted. Further bivariate assessment of the performance (CGPA) of completed master's students $(n=430)$ by their completion time, adopting the Spearman's Rank correlation test, yielded a non-significant association at a five percent level $(\mathrm{p}=$ 0.1206). However, the performance of the completed students, in the Kruskal-Wallis test, was significantly associated with their entry qualifications represented by their Bachelor CGPA $\left(\chi^{2}=11.0, p<0.01\right)$. These findings suggest that the entry criteria are a better predictor of academic performance than they are a factor that affects timely completion. Because the master's studies in question require both coursework and research, they can be considered similar to doctoral studies.

Unlike prior research on doctoral studies at the University that identified the age at commencement of a doctoral program as a key factor that influences timely completion (Wamala et al., 2011), this work suggests otherwise for the master's programs at the University. This difference is likely due to the variation in the age distribution of the graduate students: master's students were of a younger age at the commencement of their studies (median, 29; range, 20-53) compared to their doctoral counterparts (median, 37; range, 24-61). This variable scored a higher probability value during the Log-Rank test compared to the entry criteria $(\mathrm{p}=0.25)$ and thus was excluded from the multivariate analysis (Hosmer, Lemeshow, \& May, 2008). In other words, its inclusion in the multivariate assessment would not yield significant changes to the log hazard estimates.

In light of the similarities established for the completion times of master's and doctoral studies at the University, the dynamics of completion time at one stage of graduate studies could be used to explain the situation in the other. However, such a generalization may not hold across various academic institutions because of the differences in academic cultures and in the characteristics of their graduate students. 


\section{AUTHOR INFORMATION}

Robert Wamala, Ph.D. Student, Institute of Statistics and Applied Economics, Makerere University, Uganda. Research Interests: Data Management, Analysis and Reporting using: STATA, SPSS, EPIINFO, EVIEWS \& EPIDATA. E-mail: rwamala@isae.mak.ac.ug

Joseph C. Oonyu, Ph.D. School of Education, Science and Technical Education Department, Makerere University, Uganda. E-mail: joonyu@educ.mak.ac.ug

\section{REFERENCES}

1. Akaike, H. (1974). A new look at the statistical model identification. IEEE Transactions on Automatic Control, AC-19, 716-723.

2. Bourke, S., Holbrook, A., \& Lovat, T. (2006). Relationships of PhD candidate, candidature and examination characteristics with thesis outcomes. Proceedings of the AARE Annual Conference, Adelaide, 27-30 November. Retrieved from http://www.aare.edu.au/06pap/bou06655.pdf

3. Bourke, S., Holbrook, A., Lovat, T., \& Farley, P. (2004). Attrition, completion and completion times of $\mathrm{PhD}$ candidates. Proceedings of the AARE Annual Conference, Melbourne, 28 Nov-2 Dec. Retrieved from http://www.aare.edu.au/04pap/bou04849.pdf

4. $\quad$ Cox, D. R., \& Oakes, D. (1984). Analysis of Survival Data. London: Chapman and Hall.

5. Hosmer, D.W., Lemeshow, S., \& May, S. (2008). Applied Survival analysis: Regression Modelling of Time event Data $\left(2^{\text {nd }}\right.$ ed. $)$.

6. D'Andrea, L. M. (2002). Obstacles to completion of the doctoral degree in colleges of education. Educational Research Quarterly.

7. Haksever, A. M., \& Manisali, E. (2000). Assessing supervision requirements of PhD students: The case of construction management and engineering in the UK. European Journal of Engineering Education.

8. Hosmer, D., Lemeshow, S., \& May, S. (2008). Applied Survival Analysis (2nd Edn.). Hoboken: Wiley Series in Probability and Statistics. ISBN: 978-0-471-75499-2.

9. Elgar, F. (2003). PhD completion in Canadian universities. Final report. Halifax, Nova Scotia: Graduate Students Association of Canada.

10. Ismail, A., \& Abidin, N. Z. (2009). Service attributes of Graduate Research Students' needs in a Malaysian University. The Journal of International Social Research, 2(6), 1-2.

11. Grebennikov, L., \& Shah, M. (2007). Enhancing the Research Student Experience at university, University of West Sydney. Proceedings of the Australasian Association for Institutional Research Forum.

12. Saint John, E., Cabrera, A., Nora, A., \& Asker, E. (2000). Economic influences on persistence reconsidered: How can finance research inform the reconceptualization of persistence models.

13. Sanders, D., Guwatudde, D., \& Alexander, L. (2008). Accessible public-health education: a potential growth area. Bull World Health Organization. 86(8), PMID: 0042-9686.

14. Sheridan, P. M., \& Pyke, S.W. (1994). Predictors of Time to Completion of Graduate Degrees. Canadian Journal of Higher Education, 12 (2), 68-88.

15. Shapiro, S. S., \& Wilk, M. B. (1965). An analysis of variance test for normality (complete samples). Biometrika, 52 (3-4): 591-611

16. Tinto, V. (1993). Leaving College: Rethinking the Causes and Cures of Student Attrition. (2 ${ }^{\text {nd }}$ ed.). Chicago. University of Chicago Press.

17. Tinto, V. (1987). Leaving College: Rethinking the Causes and Cures of Student Attrition (1st ed.). Chicago: University of Chicago Press.

18. Makerere University (2009). Human Resource Manual (pp.53). Retrieved from http://intranet.mak.ac.ug

19. Mugimu, C. B., Nakabugo, M. G., \& Katunguka, R. E. (2009). Exploring Factors Affecting Staff Research Output and Completion Rates of Graduate Students in Makerere University - status report as of 21 November 2010. Kampala: Makerere University.

20. Vladimir, J. (2010). Potential predictors of timely completion among dissertation research students at an Australian faculty of sciences. International Journal of Doctoral Studies. 
21. Wamala, R., Oonyu, J., \& Ocaya, B. (November, 2011). Likelihood of Completion and Extended candidature of a Ph.D. A Five-year Analysis of Studies at Makerere University. Proceedings of the $8^{\text {th }} \mathrm{PhD}$ Seminar Series at Makerere University. Deputy Vice-chancellor (AA). Retrieved from http://mak.ac.ug/documents/8thPhDDissemAbstractRobertWamala.pdf

22. Wamala, R., Oonyu, J., \& Ocaya, B. (2011). Completion time dynamics of doctoral studies at Makerere University: A hazard model evaluation. Journal of International Education Research (JIER), 7(3), 49-58

23. Wisdom, J. T. (2010). Challenges of developing and retaining the next generation of academics: Deficits in academic staff capacity at African Universities. Report Commissioned by Partnership for Higher Education in Africa

24. Wisdom, J. T. (2008). Comparative Analysis of Next Generation of Academics Indicators. Proceedings of the University Leaders' Forum. Accra, Ghana 
NOTES 